Vol.25, No.2, Desember 2019

ISSN (p): 1693-590x, ISSN (e): 2686-4711

DOI: $10.36309 /$ goi.v25i2.110

\title{
Aplikasi Pemesanan Barang pada Unit Produksi Percetakan SMK Grafika Berbasis Android
}

\author{
Isadora Nugroho ${ }^{1}$, Haryanto ${ }^{2}$, Ambar Saputri ${ }^{3}$ \\ ${ }^{13}$ Program Studi Sistem Informasi, STMIK AUB, Surakarta, Indonesia \\ ${ }^{2}$ Program Studi Sistem Komputer, STMIK AUB, Surakarta, Indonesia \\ e-mail: *1 isadora.nugroho@stmik-aub.ac.id, ${ }^{2}$ haryanto@stmik-aub.ac.id, ${ }^{3}$ \\ ambars99@gmail.com
}

\begin{abstract}
Abstrak
Smartphone atau yang biasa dikenal dengan Ponsel merupakan salah satu wujud dari perkembangan teknologi yang dapat mempersempit ruang maupun waktu. Fungsi ponsel sekarang tidak hanya menjadi alat komunikasi saja akan tetapi sudah menjadi sarana hiburan dan juga gaya hidup. Aplikasi pemesanan barang pada unit produksi percetakan berbasis android ini bisa menjadi suatu sistem atau aplikasi yang sangat membantu pelanggan percetakan dalam mengumpulkan informasi dan melakukan pemesanan barang, karena bisa diakses dimanapun. Aplikasi Pemesanan Barang Pada Unit Produksi Percetakan SMK Grafika Berbasis Android, dibangun menggunakan metode deskriptif dengan jenis penelitian studi kasus di Kota Surakarta. Teknik analisa kelemahan sistem menggunakan analisa PIECES (Perfomance, Information, Economy, Cotrol, Efficiency, dan Service). Untuk teknik pengembangan sistem menggunakan metode waterfall, sedangkan untuk menggambarkan alur data menggunakan Data Flow Diagram yang terdiri dari diagram konteks, Data Flow Diagram level 0, Data Flow Diagram Level 1 dan Data Flow Diagram Level 2. Software yang digunakan untuk membangun sistem ini adalah Android Studio dan XAMPP sebagai koneksi database MySQL. Berdasarkan pengujian yang telah dilakukan menggunakan blackbox testing, sistem yang dibangun dapat membantu masalah yang dihadapi unit produksi percetakan dan pelanggan.
\end{abstract}

Kata kunci: Percetakan, Aplikasi pemesanan barang pada unit percetakan berbasis android, Android Studio, XAMPP

\section{PENDAHULUAN}

Perkembangan informasi dan komunikasi dari waktu ke waktu terus mengalami peningkatan. Smartphone merupakan salah satu wujud dari perkembangan teknologi yang dapat mempersempit ruang maupun waktu. Fungsi Smartphone tidak hanya sebagai alat komunikasi saja melainkan menjadi sarana hiburan atau sarana untuk memesan produk. Dengan menggunakan Smartphone informasi dapat diakses secara cepat, tepat, serta akurat.

Android adalah sistem operasi berbasis linux yang dirancang untuk perangkat bergerak layar sentuh seperti telepon pintar Smartphone dan komputer tablet. Android awalnya dikembangkan oleh Android,Inc. didirikan di Palo Alto, California pada bulan oktober 2003 oleh Andi Rubin, Rich Miner, Nick Sears, dan Chris White dengan dukungan finansial dari Google yang kemudian membelinya pada tahun 2005. Sistem operasi ini dirilis secara resmi pada tahun 2007. Android merupakan sistem operasi dengan sumber terbuka dan Google merilis kodenya di bawah Lisensi Apache, yang memungkinkan perangkat lunak untuk dimodifikasi secara bebas dan didistribusikan oleh para pembuat perangkat, operator nirkabel, dan pengembang aplikasi yang umumnya ditulis dalam versi kustomisasi Bahasa pemrograman

Received November 11, 2019; Revised November 25, 2019; Accepted December 9, 2019 
Java. Pada bulan Oktober 2013 ada lebih dari satu juta aplikasi yang tersedia untuk Android, dan sekitar 50 miliar aplikasi telah diunduh dari Google Play, toko aplikasi utama Android.

Sejarah percetakan di Indonesia dimulai tahun 1659. Pada tahun 1659 telah masuk barang percetakan pertama yang diberi nama Almanak Tijdbuek. Diperkirakan sekitar abad ke17 nederland tertarik membuka usaha percetakan di Indonesia yaitu Jakarta. Menerbitkan karya berupa puisi, almanak, surat kabar dan kamus. Pada tahun 1976 ada sebanyak 385 mesin cetak offset didatangkan ke Indonesia. Perkembangan pesat dimulai pada tahun 1992 sampai 1997 dimana Teknologi Computer To Film (CTF) mulai masuk ke Indonesia dari percetakan besar hingga kecil. Pada tahun 2000 penggunaan CTF mulai teralihkan perihal perkembangannya teknologi Computer To Plate (CTP). Perkembangan terkini percetakan di Indonesia tumbuh pesat dengan CTP, kemudian era 2007 keatas muncul berbagai peluang menjanjikan seperti Digital Printing, 3D Printing, dan Water Transfer Printing.

Inigo Press merupakan unit produksi SMK Grafika yang berjalan dibidang percetakan. Melayani desain cetak yang beragam antara lain cetak brosure, pamflet, kartu nama, undangan, dus kemasan, pin, mug gelas, dll. Promosi dan jangkauan pemasaran dengan keterbatasan tenaga kerja dalam hal pemasaran jasa dan produk yang akan dijual adalah salah satu hambatan bagi Inigo Press. Dengan bantuan teknologi dan informasi menjadikan usaha ini dapat memudahkan melakukan pemasaran dengan jangkauan lebih luas tanpa harus membayar tenaga pemasaran untuk menawarkan jasa dan produk. Penelitian yang telah dilakukan pada Percetakan Inigo Press dimana masih menggunakan sistem konvensional untuk melakukan pemesanan jasa cetak sehingga percetakan Inigo Press mempunyai masalah yang sering terjadi seperti sulitnya pemesanan. Maka dengan menghasilkan sebuah aplikasi berbasis Android akan dapat mempermudah proses transaksi pemesanan di percetakan Inigo Press.

Aplikasi pemesanan barang pada unit produksi percetakan SMK Grafika berbasis Android ini bisa menjadi sumber informasi bagi customer agar dapat mengetahui jenis barang dan harga yang diproduksi oleh unit produksi SMK Grafika, selain itu juga dapat mempermudah proses pemesanan.

Berdasarkan dari uraian latar belakang masalah diatas, maka dapat dirumuskan masalah yaitu, "Bagaimana merancang dan membangun Aplikasi Pemesanan barang pada unit produksi SMK Grafika Berbasis Android, agar dapat mengetahui jenis dan harga barang yang diproduksi oleh unit produksi percetakan SMK Grafika, selain itu juga dapat mempermudah proses pemesanan?".

\section{METODE PENELITIAN}

\subsection{Analisis PIECES}

Untuk menganalisa kelemahan sistem diperlukan langkah untuk mengidentifikasi dan memberikan solusi terhadap kelemahan sistem yang ada, maka sebagai landasan penulis menggunakan metode atau kerangka PIECES yang terdiri dari performance, information, economy, control, efficiency dan service. Analisis pada tabel 1 ini digunakan sebagai alat ukur untuk menentukan sistem baru layak atau tidak karena enam aspek ini harus mengalami peningkatan ukuran yang lebih baik dan sistem lama agar dapat mendukung dalam kelancaran proses media promo percetakan.

\begin{tabular}{|l|l|l|}
\multicolumn{3}{c}{ Tabel 1 Analisis PIECES } \\
\hline \multicolumn{1}{|c|}{ Analisa } & \multicolumn{1}{|c|}{ Sistem Lama } & \multicolumn{1}{c|}{ Sistem Baru } \\
\hline $\begin{array}{l}\text { Perfomance } \\
\text { (Kinerja) }\end{array}$ & $\begin{array}{l}\text { Membutuhkan waktu lama untuk } \\
\text { memilih produk yang akan dipesan } \\
\text { karena harus datang langsung ke } \\
\text { tempat percetakan. }\end{array}$ & $\begin{array}{l}\text { User bisa langsung memilih dan memesan } \\
\text { barang dengan mengakses aplikasi } \\
\text { menggunakan smartphone. }\end{array}$ \\
\hline $\begin{array}{l}\text { Information } \\
\text { (Informasi) }\end{array}$ & $\begin{array}{l}\text { Kurangnya tenaga marketing } \\
\text { menjadikan informasi seputar barang } \\
\text { dan harga barang kurang tersebar luas } \\
\text { ke masyarakat. }\end{array}$ & $\begin{array}{l}\text { Informasi seputar barang cetak bisa diketahui } \\
\text { secara detail, jadi tidak harus datang langsung } \\
\text { ke percetakan. }\end{array}$ \\
\hline
\end{tabular}

Aplikasi Pemesanan Barang pada Unit Produksi Percetakan SMK Grafika Berbasis Android 


\begin{tabular}{|l|l|l|}
\hline $\begin{array}{l}\text { Economy } \\
\text { (Ekonomi) }\end{array}$ & $\begin{array}{l}\text { Pemasukkan percetakan inigo press } \\
\text { selalu meningkat dari tahun ke tahun } \\
\text { sehingga mampu menghasilkan } \\
\text { ekonomi yang tinggi. }\end{array}$ & $\begin{array}{l}\text { Dengan adanya sistem baru maka proses } \\
\text { pemesanan bisa lebih mudah, dan membuat } \\
\text { pemasukkan percetakan inigo press lebih } \\
\text { meningkat. }\end{array}$ \\
\hline $\begin{array}{l}\text { Control } \\
\text { (Pengendalia } \\
\text { n) }\end{array}$ & $\begin{array}{l}\text { Ketika desain sudah di acc oleh } \\
\text { pelanggan maka proses cetak } \\
\text { langsung dilaksanakan. }\end{array}$ & $\begin{array}{l}\text { Proses acc dilakukan dengan mengirim } \\
\text { melalui e-mail. }\end{array}$ \\
\hline $\begin{array}{l}\text { Efficiency } \\
\text { (Efisiensi) }\end{array}$ & $\begin{array}{l}\text { Pelanggan harus datang bertatap } \\
\text { muka berkali-kali sampai desain acc. }\end{array}$ & $\begin{array}{l}\text { Lebih efisiensi karena bisa dilakukan dimana } \\
\text { saja. Untuk acc desain bisa dikirim melalui e- } \\
\text { mail. }\end{array}$ \\
\hline $\begin{array}{l}\text { Service } \\
\text { (Layanan) }\end{array}$ & $\begin{array}{l}\text { Layanan untuk pelanggan } \\
\text { membutuhkan waktu lama karena } \\
\text { proses desain harus sampai acc dan } \\
\text { dilakukan ditempat percetakan. }\end{array}$ & $\begin{array}{l}\text { Layanan terhadap pelanggan akan lebih baik } \\
\text { dengan adanya sistem mempermudah } \\
\text { pelanggan untuk melakukan proses } \\
\text { pemesanan. }\end{array}$ \\
\hline
\end{tabular}

\subsection{Analisis Kebutuhan Informasi}

Kebutuhan Aplikasi Pemesanan Barang Pada Unit Produksi Percetakan SMK Grafika

Berbasis Android dimana didalamnya memuat informasi antara lain: informasi data barang yang diproduksi beserta spesifikasinya, dan informasi harga barang.

\subsection{Analisis Kebutuhan Pengguna}

Pengguna aplikasi di Aplikasi Pemesanan Barang di Solo Berbasis Android ini antara lain:

a. User atau pengguna adalah orang-orang yang menggunakan fasilitas dari sistem ini untuk membantu dalam mencari informasi dan harga barang yang diproduksi.

b. Admin atau pengelola adalah orang-orang yang mengelola sistem dalam membantu memenuhi informasi barang yang diproduksi beserta harga barang.

2.4 Flowchart Sistem Pengolahan Informasi Data Barang yang diusulkan.

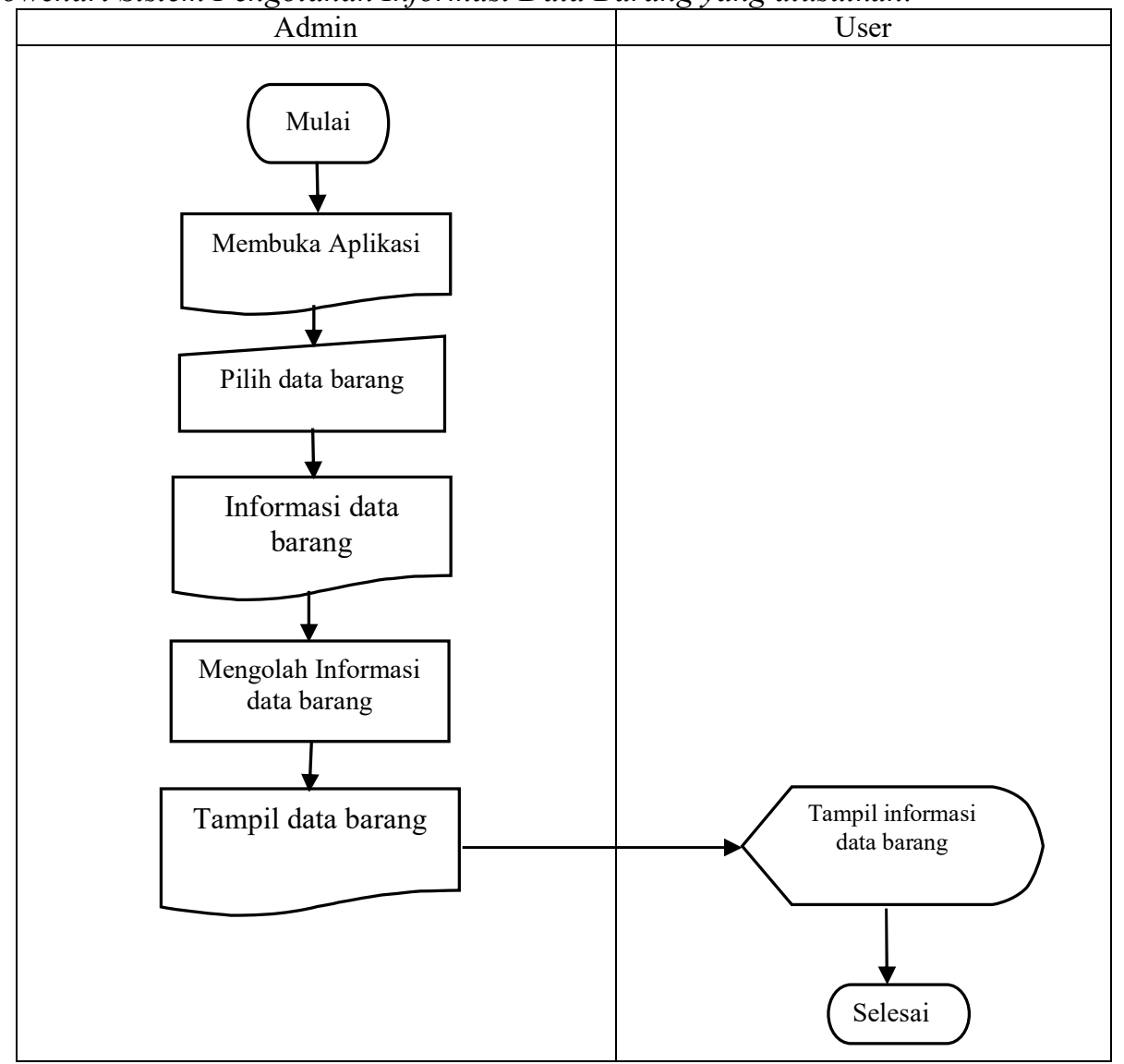

Gambar 1 Flowchart sistem proses pengolahan informasi data barang

GO INFOTECH: JURNAL ILMIAH STMIK AUB Vol. 25, No. 2, Desember 2019: 122-132 
Keterangan gambar 1 Flowchart sistem yang akan dibangun proses pengolahan informasi data barang, admin membuka halaman aplikasi admin kemudian memilih data barang yang akan dimasukkan. Data yang diinputkan oleh admin akan tersimpan pada database dan akan tampil pada menu data barang dan menu katalog pada aplikasi user.

2.5 Flowchart Sistem Proses Pemesanan Barang

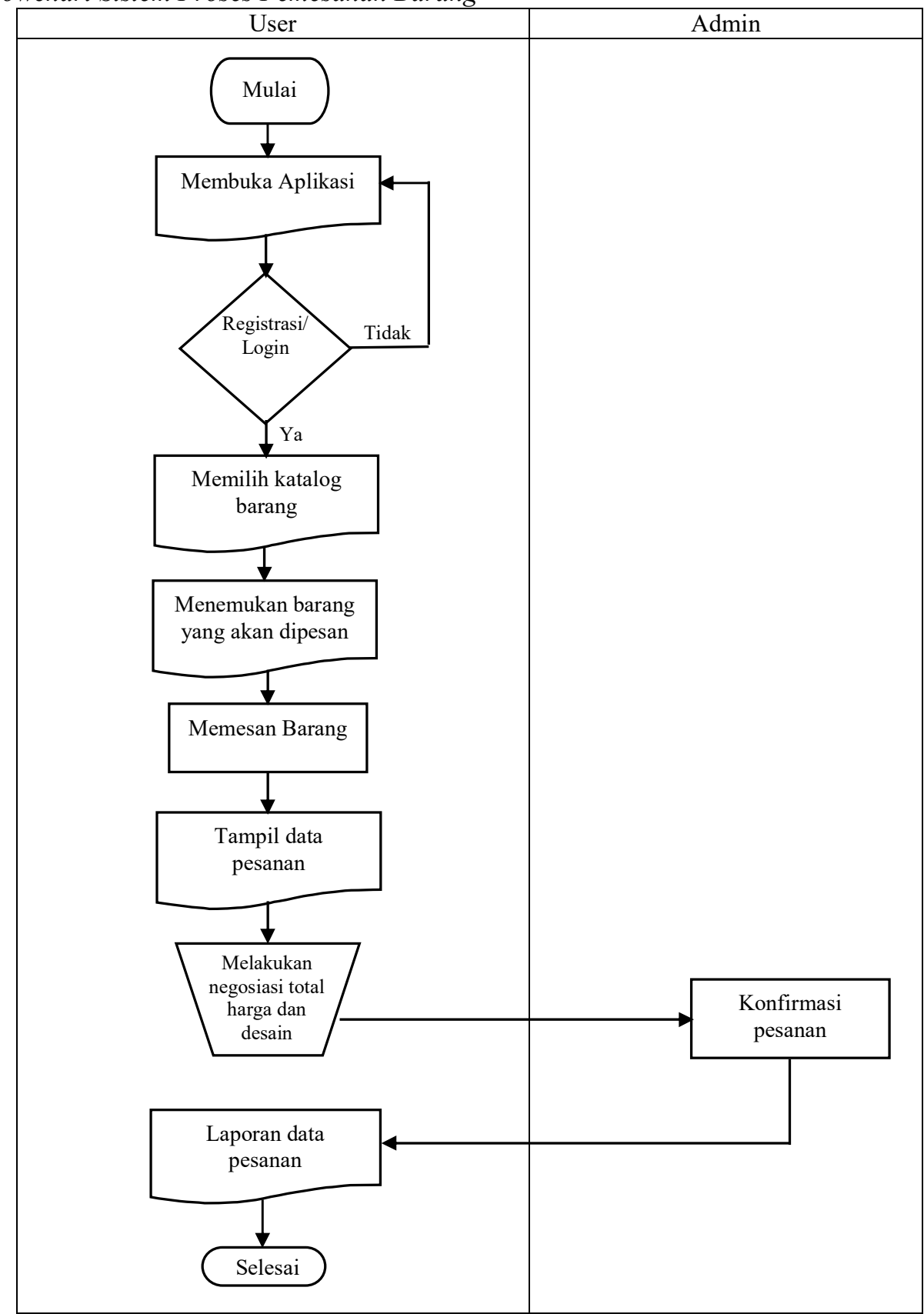

Gambar 2 Flowchart sistem proses pemesanan barang

Pada gambar 2 flowchart sistem proses pemesanan barang, user membuka aplikasi, kemudian membuka menu katalog barang, setelah itu melakukan registrasi bagi yang belum terdaftar, dan melalukan login jika sebelumnya sudah melakukan daftar. untuk login dengan memasukkan username dan password agar dapat memilih katalog barang yang akan dipesan. Jika sudah menemukan barang yang akan dipesan maka langsung melakukan proses pemesanan. Selanjutnya akan melakukan negosiasi total harga dan desain dengan menghubungi admin

Aplikasi Pemesanan Barang pada Unit Produksi Percetakan SMK Grafika Berbasis Android 
melalui telepon dan email. Setelah total harga dan desain diputuskan maka admin akan melakukan konfirmasi pesanan dengan memasukkan total harga dan pembayaran uang muka, setelah itu akan muncul laporan data pesanan secara detail pada halaman user.

2.6 Diagram Konteks

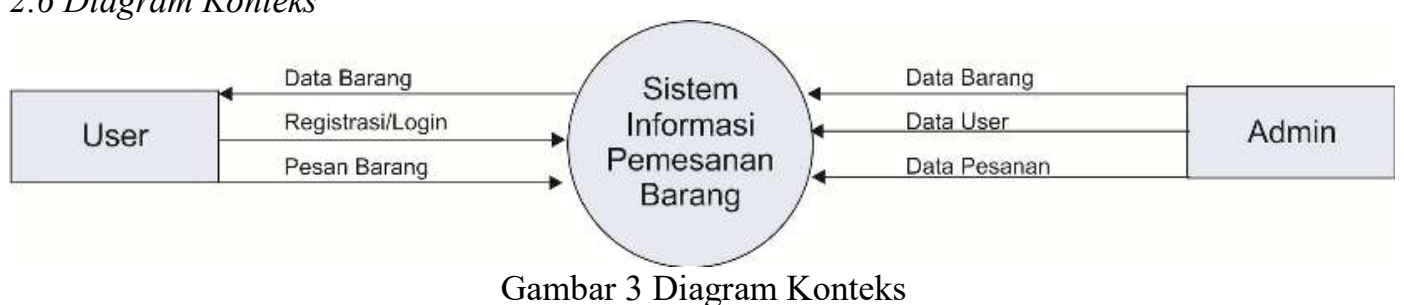

Diagram konteks Aplikasi pemesanan barang pada unit produksi percetakan SMK Grafika berbasis Android, admin dapat mengelola data user, data barang, serta data pesanan. Untuk user melakukan registrasi atau login dan setelah itu dapat melakukan aktivitas melihat katalog barang dan memesan barang.

2.7 Relasi Antar Tabel

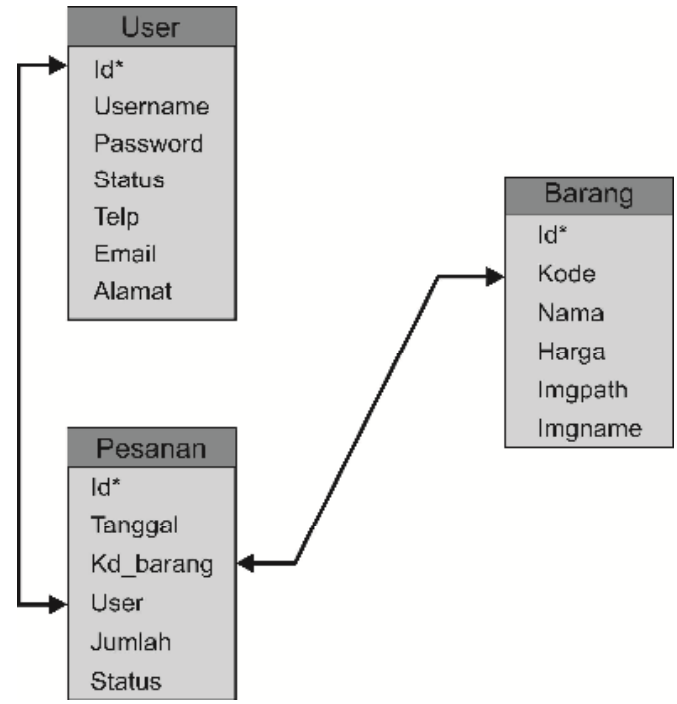

Keterangan: * Primary Key

Gambar 4 Relasi Antar Tabel

\section{HASIL DAN PEMBAHASAN}

\subsection{Hasil}

Berikut adalah proses pembahasan interface atau antarmuka program:

1. Halaman form utama aplikasi Inigo Press Admin

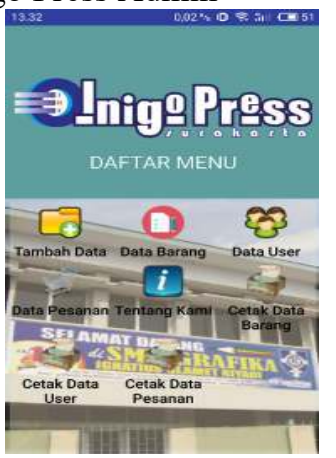

Gambar 5 Form utama aplikasi Inigo Press Admin 
Gambar 5 halaman form menu utama aplikasi Inigo Press Admin, merupakan halaman awal aplikasi untuk admin.

2. Halaman Form Menu Data Barang

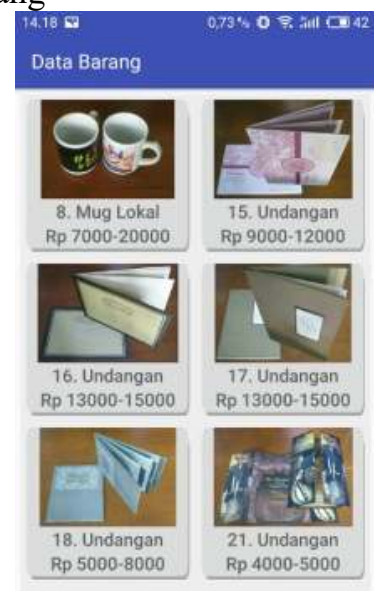

Gambar 6 Halaman form menu data barang

Halaman form menu data barang gambar 6 merupakan halaman yang berisi data barang yang telah sukses di input oleh admin pada form tambah barang.

3. Halaman Form Menu Data User

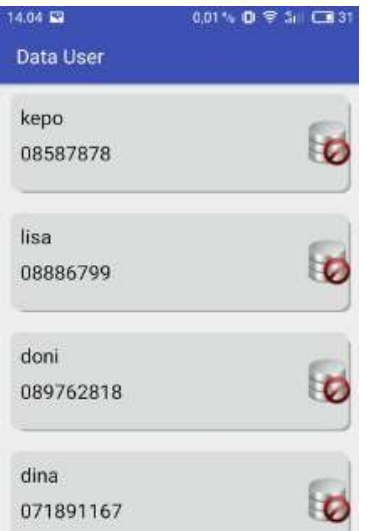

Gambar 7 Halaman form menu data user

Halaman form menu data user gambar 7 merupakan halaman yang berisi data user. Semua user yang telah berhasil mendaftar, datanya akan masuk kedalam data user tersebut.

4. Halaman Form Menu Data Pemesanan

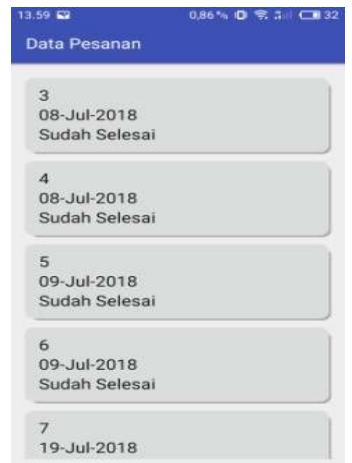

Aplikasi Pemesanan Barang pada Unit Produksi Percetakan SMK Grafika Berbasis Android 
Gambar 8 Halaman Form Menu Data Pemesanan

Pada gambar 8 halaman form menu data pesanan merupakan halaman yang berisi data pesanan user. Ada 2 jenis yaitu belum selesai dan sudah selesai. Sudah selesai artinya sudah dikonfirmasi oleh admin, belum selesai artinya belum dikonfirmasi.

5. Halaman Form Preview Pemesanan

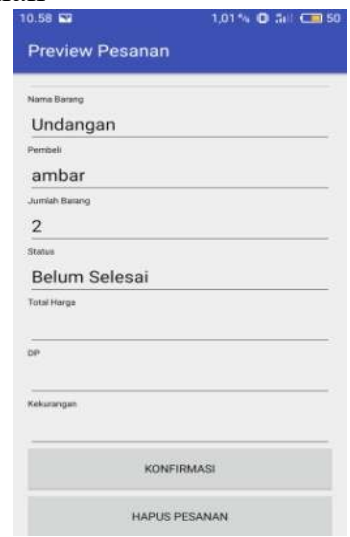

Gambar 9 Halaman form preview pemesanan

Halaman form preview pesanan pada gambar 9 merupakan halaman untuk melakukan konfirmasi pesanan. Admin harus mengisi data total harga, DP, dan kekurangan terlebih dahulu, setelah itu dikonfirmasi.

6. Halaman Form Cetak Data Barang

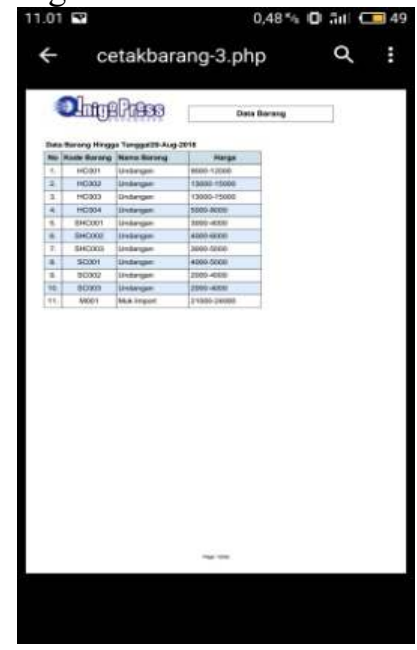

Gambar 10 Halaman form cetak data barang

7. Halaman Form Cetak Data Pemesanan

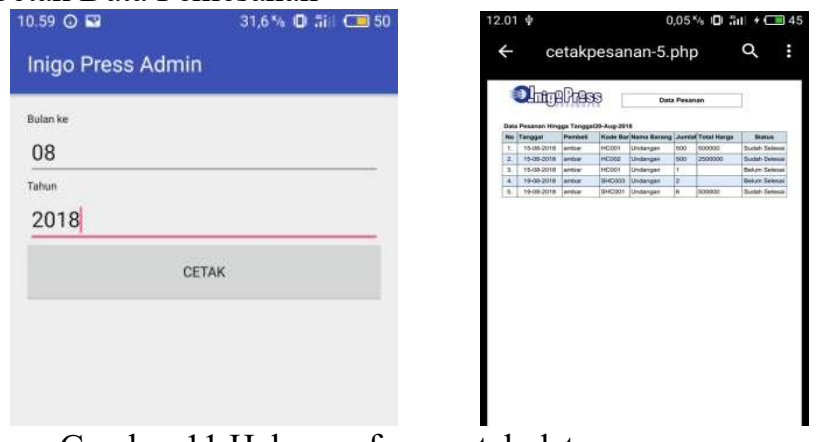

Gambar 11 Halaman form cetak data pemesanan 
Halaman menu cetak data pesanan gambar 11 merupakan halaman yang berisi data pesanan dalam bentuk file .pdf untuk dapat membuka nya maka harus diunduh terlebih dahulu. Sebelum di cetak harus memasukkan bulan dan tahun yang akan dicetak terlebih dahulu. Data pesanan dibuat periode setiap bulan.

8. Halaman Form utama Aplikasi Inigo Press user

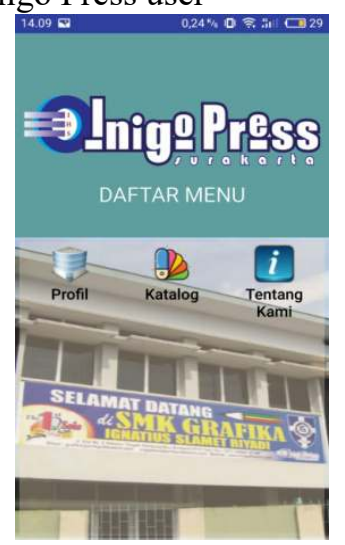

Gambar 12 Halaman form utama aplikasi inigo press user

Pada gambar 12 halaman form menu utama Aplikasi Inigo Press user, merupakan halaman awal aplikasi user.

9. Halaman Form Daftar User

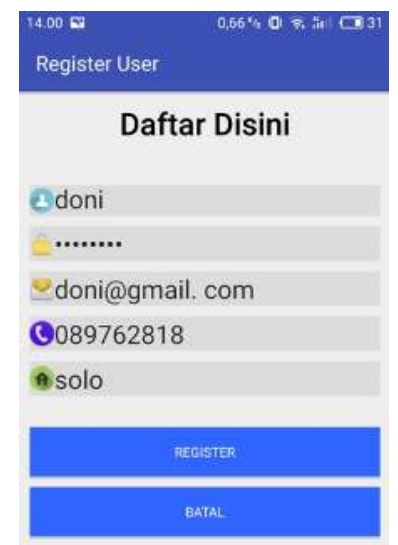

Gambar 13 Halaman form daftar user

10.Halaman Form Katalog Barang 


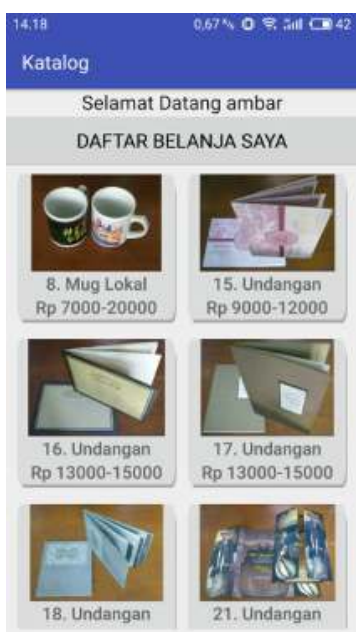

Gambar 13 Halaman form katalog barang

11.Halaman Form Data Pemesanan

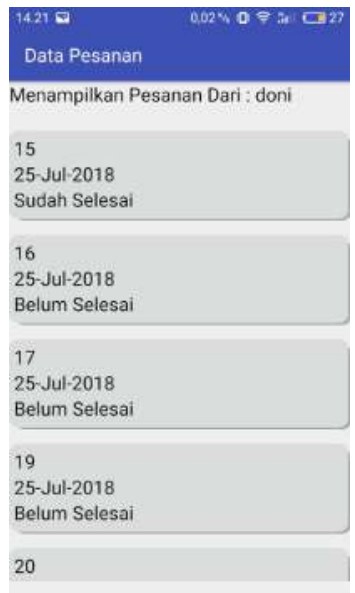

Gambar 14 Halaman form data pemesanan user

Gambar 14 halaman form data pesanan, merupakan halaman pesanan dari user. Status Belum selesai jika pesanan belum dikonfirmasi oleh admin.

12.Halaman Form Konfirmasi Pesanan

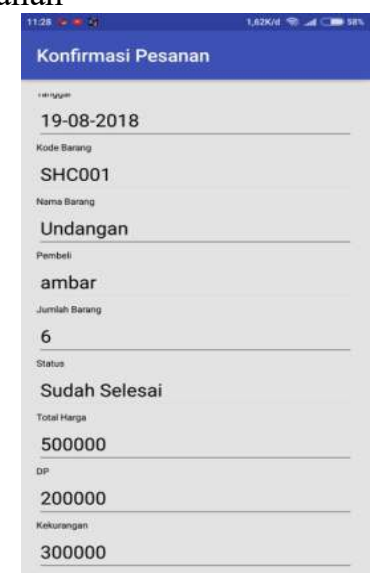

Gambar 15 Halaman form konfirmasi pesanan 
Halaman form konfirmasi pesanan gambar 15 merupakan halaman konfirmasi pesanan user yang berisi tentang laporan data pesanan yang sudah dikonfirmasi oleh admin. Setelah dikonfirmasi oleh admin maka status pesanan akan berubah menjadi Sudah Selesai.

\section{KESIMPULAN}

Hasil perancangan aplikasi pemesanan barang pada unit produksi percetakan SMK Grafika Solo Berbasis Android terdiri dari flowchart, diagram konteks, data flow digram level 0, data flow diagram level 1 , data flow diagram level 2. Pengembangan sistem menggunakan bahasa pemrograman Java dan Android Studio sebagai IDE dan database MySQL. Aplikasi pemesanan barang pada unit produksi percetakan SMK Grafika Solo Berbasis Android, digunakan sebagai media untuk memesan barang cetak yang bisa langsung diproses dengan menggunakan smartphone. Adanya aplikasi pemesanan barang pada unit produksi percetakan SMK Grafika Solo ini diharapkan dapat mempermudah proses pemesanan dengan cepat dan mudah tanpa harus datang langsung ketempat percetakan.

\section{SARAN}

Aplikasi Pemesanan barang pada unit Produksi Percetakan SMK Grafika Solo Berbasis Android ini, masih dapat dikembangkan lebih lanjut, yaitu: Untuk Halaman menu utama user ditambahkan fitur promosi yang berisi katalog harga promo yang sedang diskon atau dengan harga yang fantastis supaya lebih menarik. Fitur promosi tersebut selalu berganti setiap bulan, jadi aplikasi akan terkesan tidak pasif, karena selalu ada yang baru dan promo menarik.

\section{DAFTAR PUSTAKA}

[1] Android.Sistem Operasi. Wikipedia Bahasa Indonesia tahun 2003.

[2] Hidayat, Rahmat. 2016. Sistem Informasi Pemesanan jasa cetak berbasis web pada CV. Vida Plus Jakarta.Skripsi:STMIK-Nusa Mandiri Jakarta.

[3] https://id.wikipedia.org/wiki/Android_(sistem_operasi)

[4] https://id.wikipedia.org/wiki/Informasi

[5] http://jurnal.unda.ac.id/index.php/Jpdf/article/download/29/29

[6] https://repository.widyatama.ac.id/xmlui/bitstream/handle/123456789/3047/Bab\%202.pdf ? sequence $=7$

[7] https://solusiprinting.com/sejarah-percetakan-di-indonesia/

[8] http://www.definisi-pengertian.com/2015/03/definisi-dan-pengertian-informasi.html

[9] http://www.pelajaran.co.id/2017/29/pengertian-sistem-informasi-menurut-ahli.html

[10] http://www.pengertianpakar.com/2014/10/pengertian-sistem-menurut-para-pakar.html

[11] http://www.sarjanaku.com/2012/11/pengertian-sistem-menurut-para-ahli.html

[12] Jogiyanto. 2005. Analisis \& Desain Sistem Informasi : Pendekatan Terstukter, Teori dan Praktis Aplikasi Bisnis. Yogyakarta : Penerbit Andi.

[13] Kamus Besar Bahasa Indonesia Edisi Ketiga Tahun 2003.

[14] Kristanto. 2003. Konsep dan Perancangan Basis Data. Yogyakarta : Penerbit Andi

[15] Ladjamudin, Albahra. 2005. Analisis dan Desain Sistem Informasi. Yogyakarta: Graha Ilmu.

[16] Nugroho, Irman D. 2017. Sistem Informasi Order Percetakan di Rovell Digital Printing. Jurnal:Universitas Komputer Indonesia.

[17] Pressman, Roger S. 2001. Software Engineering : A Practitioner's Approach Fifth Edition. Singapore : The Mc-Graw-Hill Companies

[18] Rahman, Fauzi. 2015. Aplikasi Pemesanan Undangan Online. Jurnal:Politeknik Negeri Tanah Laut Kalimantan Selatan.

Aplikasi Pemesanan Barang pada Unit Produksi Percetakan SMK Grafika Berbasis Android 
[19] Safaat, Nazrudin.2012. Android Pemrograman Aplikasi Mobile Smartphone dan Tablet PC Berbasis Android. Bandung: Informatika Bandung.

[20] Sutabri, Tata. 2005. Sistem Informasi Manajemen. Yogyakarta: Andi Offset.

[21] Winter, Opray. http://indoskripsi.com diakses pada 21 September 2016. Definisi Pengertian dan Fungsi XAMPP Lengkap 